\title{
Risk Aversion and the Investment Horizon: A New Perspective on the Time Diversification Debate
}

\author{
Sanjiv Jaggia and Satish Thosar
}

\begin{abstract}
Investment managers generally subscribe to the principle of time diversification. This implies that a larger portion of the portfolio should be devoted to risky assets as the investment horizon increases. In contrast, academics have shown that for investors with utility functions characterized by constant relative risk aversion, the optimal asset-allocation strategy is independent of the investment horizon. The relative risk aversion in these studies is assumed to be constant both with respect to wealth as well as investment horizon. We suggest a utility function that explicitly captures the notion that individuals are more risk tolerant when the investment horizon is long, thereby validating the intuitively appealing time diversification argument.
\end{abstract}

Most investment practitioners subscribe to the time diversification principle, which states that portfolio risk declines as the investment horizon lengthens. Accordingly, practitioners commonly advise younger clients to allocate a larger proportion of their retirement money to risky assets than older clients do. In contrast, many respected theorists argue that time diversification is a fallacy. ${ }^{1}$ Using the law of large numbers, it can be shown that the sampling variance of independent annual stock returns approaches zero as the investment horizon approaches infinity. However, this logic is flawed since investors care about terminal wealth, and the variance of terminal wealth increases indefinitely with the investment horizon. Samuelson (1969) shows that if stock returns follow a random walk and investors exhibit constant relative risk aversion (CRRA), the optimal asset-allocation decision is independent of the investment horizon - seemingly a clear refutation of the time diversification argument. This issue is a major unresolved controversy in the investment business. If indeed time diversification is a flawed concept, millions of small and large investors have been ill advised.

The idea of time diversification is intuitively appealing and generally deep rooted in the practitioner community. Consequently, considerable effort has been devoted both by practitioners and academics to counter the Samuelson position. For instance, researchers have examined downside or shortfall risk. One such measure is the probability that a given portfolio will earn less than some benchmark, typically the return on Treasuries, for a specific holding period. Most studies employ simulation and, predictably, the results are sensitive to the data generation process and the nature of the return series employed. For instance, Reichenstein and Dorsett (1995) conclude that "after 20 years, an investor can be 90 percent confident that portfolios with at least a 20 percent stock exposure will earn more than Treasury bills." In contrast, Leibowitz and Langetieg (1989) claim that there is a 24 percent chance that stocks will under-perform bonds over twenty years. Though often difficult to reconcile with each other, shortfall risk studies have value in that investors have a rough gauge to measure their own risk tolerance and make better-informed allocation decisions. However, the time diversification question is partially sidestepped rather than tackled head on.

Other researchers have questioned the validity of the assumptions used to attack the time diversification argument. Perhaps security returns do not follow a random walk or investors' utility functions are not characterized by the CRRA property or both. Knocking down either assumption is sufficient to overturn the fallacy argument. Samuelson (1991) and Kritzman (1994) show that the time diversification principle can be justified if there is mean reversion in stock returns. Although there is some evidence that stock returns are mean-reverting especially when measured over yearly or even longer time intervals, the statistical power of the tests is low. ${ }^{2}$ Further, since the strength of mean reversion inevitably wanes, the proportion invested in risky assets cannot increase indefinitely with the in- 
vestment horizon. Thorley (1995) uses a utility function with decreasing relative risk aversion to validate the time diversification position. However, the CRRA property has generally been well grounded in the literature.

In our opinion, the answer lies not so much in the examination of historical price data to construct alternative risk measures, nor in teasing out the "true" stock price process. Rather, the answer lies in taking a closer look at what we know about the psychology of risk-taking, particularly as it relates to time horizon. People generally feel comfortable with allocating a larger proportion of their portfolio to equities if their investment horizon is long. Perhaps the justification of this behavior comes not from the fact that risk declines over time but rather that investors are subjectively more risk-tolerant given longer horizons. In this paper, we recognize that it is the individual's risk perception interacting with the inherent risk associated with investment choices that drives the asset-allocation decision. And, crucially in favor of the time diversification position, we argue that risk perception is not only a function of age (and other cross-sectional idiosyncratic factors) but also of the temporal distance between the initial investment point and the cash-out point typically represented by the individual's retirement.

\section{The Psychology of Risk-Taking}

A number of psychological studies have documented the inverse relationship between age (or temporal distance) and risk-taking (or risk-assessment). Vroom and Pahl (1971) administered a standard choice-dilemma questionnaire to 1,484 male managers employed in over 200 corporations. Respondents had to choose between a safe, certain outcome versus a more desirable, riskier alternative. Examples include: a married engineer has to decide between a safe, secure job and a fledgling company that offers more responsibility and advancement; or the captain of a college football team has to decide between a sure play to tie or a risky play to win. The authors report a strong and significantly negative relationship between age and measures of risk-taking. Obviously, cultural and environmental factors affect risk attitudes and youth per se may be an attribute that favors risk tolerance. However, our interpretation is that younger managers are more willing to choose the riskier alternative simply because they intuitively realize that if things did go wrong they have ample time left in their professional career to start something afresh. ${ }^{3}$ We suggest that it is the career time horizon that plays the major role in shaping their risk attitude.

The case of academic tenure is instructive by analogy. Consider a forty-year old Associate Professor with tenure versus a thirty-year old Assistant Professor on a tenure track, i.e., working toward tenure. Arguably, the former is more risk tolerant in terms of a research agenda as well as investment decisions such as buying real estate or risky securities. While the age factor in isolation may point to the younger individual as being more risk tolerant, his horizon is dictated by the tenure decision year and is therefore shorter than that of the tenured professor. Clearly, the operative time horizon influences one's risk attitude.

In a recent study, Gilovich, Kerr and Medvec (1993) examine the effect of temporal perspective on subjective confidence. The authors report that people tend to lose confidence in their prospects for success as they come closer to the "moment of truth." Under controlled conditions, the researchers find that students think they will do better on their midterm exams when asked on the 1st day of class than when asked on the day of the exam. Stated differently, the students' risk-assessment becomes more conservative with shorter temporal distance.

It appears that the general human attitude towards risk squares rather nicely with the idea of time diversification. If younger managers on average "go for it on fourth down" while older managers "punt," then perhaps younger investors have more aggressive asset-allocation strategies than older ones simply because they happen to be more risk-tolerant and not because portfolio risk declines as the investment horizon lengthens. If tolerance for risk is indeed directly related to the investor's investment horizon, it makes sense to capture this explicitly in the utility function.

\section{A Modified Utility Function}

We retain the CRRA property while recognizing the investment horizon versus risk-taking relationship that characterizes human behavior. The CRRA property implies that the selection of the portfolio proportions is independent of the investor's initial wealth, W. Consider the following power utility function that implies CRRA:

$$
\mathrm{U}(\mathrm{W})=\frac{\delta}{\delta-1}(\mathrm{~W})^{1-1 / \delta} ; \delta>0 \text { and } \mathrm{W}>0 .
$$

The relative risk-aversion measure, $R_{R}(W)$, is:

$$
\mathrm{R}_{\mathrm{R}}(\mathrm{W})=-\mathrm{W} \frac{\mathrm{U}^{\prime \prime}(\mathrm{W})}{\mathrm{U}^{\prime}(\mathrm{W})}=\frac{1}{\delta}
$$

Note that this measure is independent of wealth. Although the above utility function recognizes cross-sectional differences among individuals, it takes no account of the investment horizon of the investor. If individual $\mathrm{A}$ is more risk-averse than individual $\mathrm{B}$, then this would be reflected in a lower $\delta$ value for A compared to B. We believe that both A and B would perceive less risk if the day of reckoning were distant rather 
than looming large. We suggest a more realistic utility function in which the risk aversion parameter is a decreasing function of the investment horizon, t. For instance, consider

$$
\delta=\delta_{\mathrm{o}} \mathrm{t}^{0.10}
$$

Note that for a given investment horizon the investor has a constant relative risk aversion given by $1 / \delta_{0} t \cdot 10$, a result that is consistent with the literature on risk aversion. The cross-sectional differences in risk aversion between individuals are captured in the value of $\delta_{0}$. However, we are suggesting a risk aversion parameter that is also time specific, becoming smaller as the investment horizon increases. Using $\delta_{0}=1 / 5$, the relative risk aversion parameter changes from 5 when $\mathrm{t}=1$ to 3.71 when $\mathrm{t}=20$ (see Figure 1).

\section{Optimal Asset Allocation}

Based on the above utility function, we demonstrate the optimal asset allocation proportions for different investment horizons. Consider the following terminal wealth at period $\mathrm{t}$ :

$$
\mathrm{W}_{\mathrm{t}}=a \mathrm{~W}_{\mathrm{o}}\left(1+\mathrm{r}_{\mathrm{r}}\right)^{\mathrm{t}}+(1-a) \mathrm{W}_{\mathrm{o}}\left(1+\mathrm{r}_{\mathrm{f}}\right)^{\mathrm{t}}
$$

where $\mathrm{W}_{\mathrm{o}}$ represents initial wealth and the realized risky and risk-free annualized returns are given by $r_{r}$ and $r_{f}$ respectively. Note that $\alpha$ is the proportion of the initial investment that is allocated to risky assets. The investor, at time $\mathrm{t}_{\mathrm{o}}$, makes an optimal allocation decision for investment horizon of $t$ years where $t=1,2,3$,
.., 20. Under the utility maximization framework, the optimal risky asset allocation is determined where the investor maximizes expected utility. Since no closed form solution exists for this problem, the optimal $a$ is determined by numerically maximizing the sample average utility of terminal wealth. The terminal wealth for varying time horizons is based on $\mathrm{W}_{\mathrm{o}}=\$ 1$ and 5000 random draws of security returns. Simulated risky returns, $r_{r}$, are drawn from a log-normal distribution with a mean and standard deviation of 8.3 percent and 17.1 percent respectively. These estimates are based on large company annual stock returns deflated by the consumer price index for the post 1947 period. We use a constant risk free rate, $\mathrm{r}_{\mathrm{f}}$, of 0.9 percent which is the real average t-bill rate for the same period.

\section{Time Diversification Resurrected}

Figure 2 shows the simulation results. When the risk aversion parameter $\delta$ is independent of the investment horizon, the optimal investment proportion $a$ in the risky asset is a near constant 55 percent. This is also predicted by the standard CRRA model, which accordingly proceeds to conclude that time diversification is a fallacy. However, when we allow the risk aversion parameter to decrease with the individual's investment horizon, we get an upward sloping a function. The optimal proportion in the risky asset rises from 55 percent for a one-year horizon to around 78 percent for a twenty year horizon. The time diversification concept lives again. It turns out that investment practitioners may in fact be providing the correct asset-allocation advice to their clients but using the wrong rationale. In-

FIGURE 1

Risk Aversion and Investment Horizon

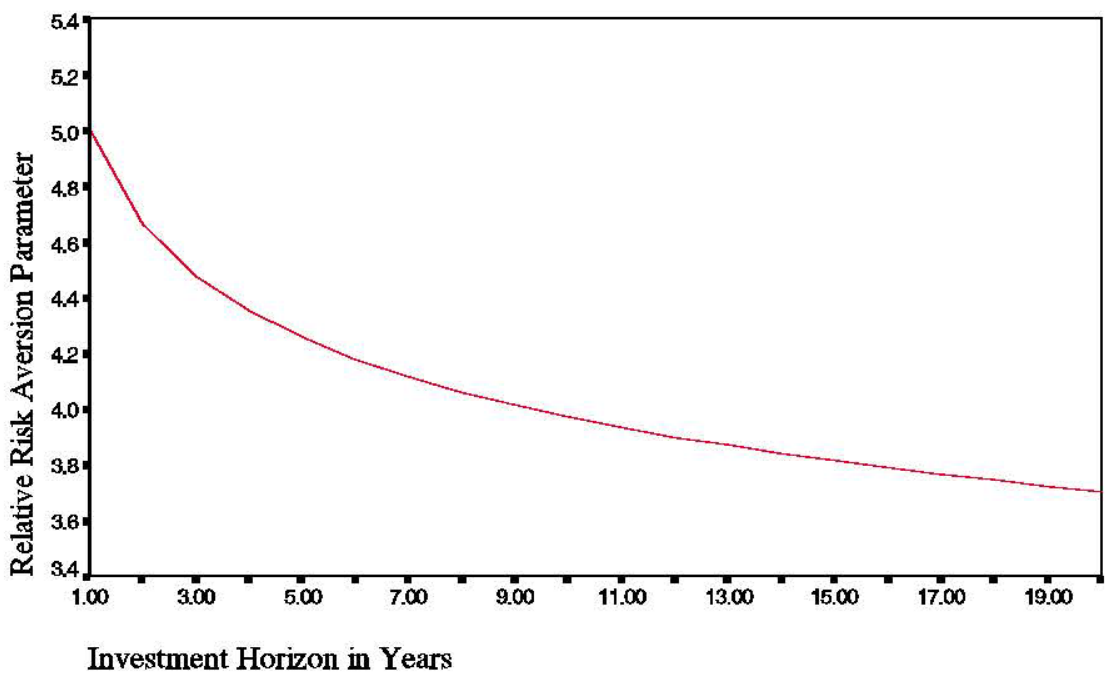

Note: The horizon dependent relative risk aversion parameter is given by $1 / \delta_{0} t^{10}$ where $\delta_{0}=1 / 5$ and $t=1,2 \ldots 20$. 
FIGURE 2

Optimal Allocation to Risky Assets Using Horizon Dependent Risk Aversion

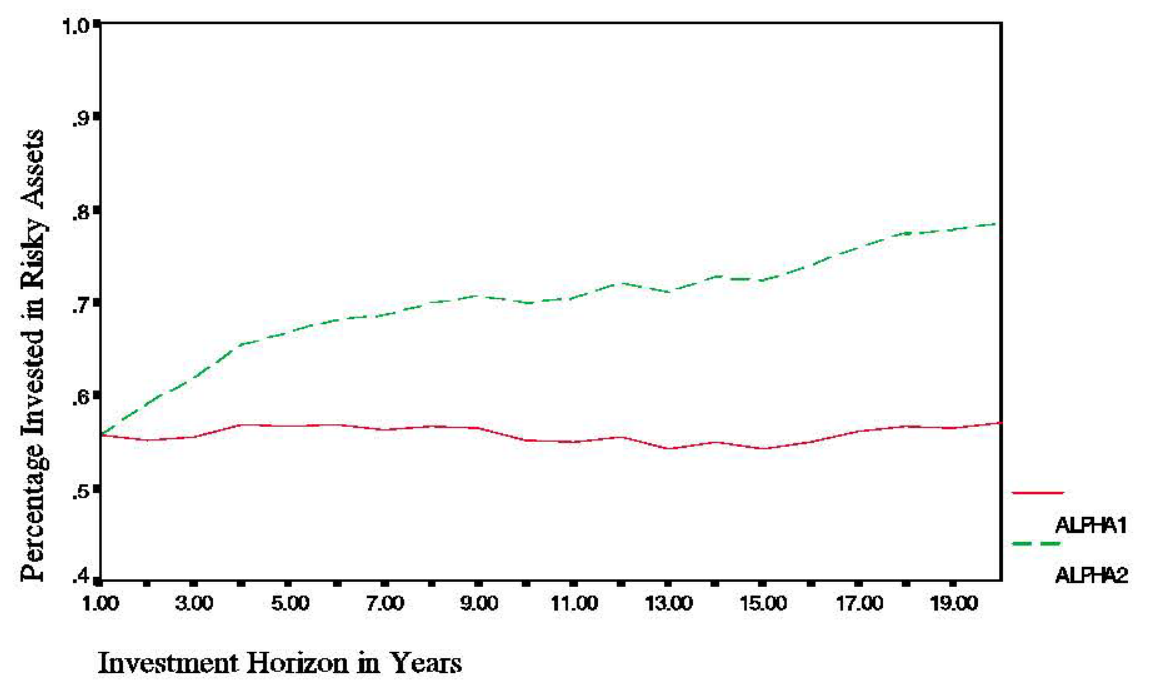

Note: The percentage invested in risky assets over the investment horizon is derived numerically on the basis of 5000 observations. Alphal is the percentage under the standard CRRA model and Alpha2 is the percentage under the modified CRRA model in which risk aversion is dependent on investment horizon.

dividuals with longer investment horizons are justified in allocating a larger proportion of their portfolio to risky assets not because good years necessarily cancel out bad years over time, but simply because they are more risk tolerant. A strictly technical interpretation of our result is that it is guaranteed given the specification of our utility function. However, we believe that a utility function that does not recognize the psychological dimension of risk perception discussed in this paper cannot really be used to compare investment choices over varying time horizons.

It should be noted that while our utility function captures an important aspect of human behavior, it suffers from a possible consistency violation. ${ }^{4}$ Let us consider a 45 -year old investor who is saving up for her retirement at the age of 65 . This investor has a 20 -year investment horizon, and consequently high risk tolerance. If she uses today as the reference point, our model suggests that she should invest 78 percent in risky assets. However, in the context of our modified utility function, she is also aware that investing such a high percent in risky assets for the entire 20 years will not appear optimal when she is 60 years old. If risk aversion is indeed horizon specific, then it may not be optimal for the investor to engage in a buy-and-hold strategy. This investor, for instance, might make a decision today to allocate a high percentage to risky assets for 15 years and lower this proportion when she reaches 60 years of age.

In conclusion, this paper offers a non-normative hypothesis that is used to rationalize observable (and testable) facts. We suggest a simple and intuitive utility function that explicitly captures the notion that individuals are more risk tolerant when the investment horizon is long, thereby validating the appealing time diversification argument. We believe that a more general model, based on this utility function, can be developed both theoretically and experimentally. There are many testable predictions that might emerge from such an analysis. For instance, our utility function may shed further light on the equity premium puzzle. Perhaps one ought not to look at the equity premium in terms of annual returns but over longer horizons. Also, it seems reasonable that shifting demographic patterns may affect risk aversion in the aggregate.

\section{Acknowledgments}

We are indebted to Professor Paul A. Samuelson for his detailed and insightful remarks. We also thank Professors Jonathan Haughton, Alison Kelly, Steven Thorley, and an anonymous referee for useful comments.

\section{Notes}

1. See, for example, Samuelson (1969), Merton (1969) and Bodie (1995).

2. See Fama and French (1988), Poterba and Summers (1988) and Siegel (1998, pp. 33-37).

3. Bodie, Merton and Samuelson (1992) show that that other things being equal, greater labor flexibility will induce greater risk taking in an individual's financial investments. In this con- 
text, younger managers can be assumed to have greater labor flexibility than older ones.

4. We thank Prof. Paul A. Samuelson for this important insight. He also pointed out that this problem has existed since the works of Böhm-Bawerk and Irving Fisher who spoke of the time perspective in discounting future pleasures of say chocolates. If jolts of pleasure from chocolates loom larger when you move closer to the contemplated consumption, then in a similar vein we argue that displeasure associated with an uncertain outcome magnifies as you move closer to the consumption point.

\section{References}

Bodie, Zvi."On the Risk of Stocks in the Long Run." Financial Analysts Journal, May-June 1995, pp. 18-22.

Bodie, Zvi, Robert C. Merton and William F. Samuelson. "Labor Supply Flexibility and Portfolio Choice in a Life Cycle Model." Journal of Economic Dynamics and Control, 16(1992), pp. 427-449.

Fama, Eugene and Kenneth French. "Permanent and Temporary Components of Stock Prices." Journal of Political Economy, Vol. 96, No. 2, 1988, pp. 269-973.

Gilovich, Thomas, Margaret Kerr and Victoria H. Medvec. "Effect of Temporal Perspective on Subjective Confidence." Journal of Personality and Social Psychology, Vol. 64, No. 4, 1993, pp. 552-560.

Kritzman, Mark. "What Practitioners need to know about Time Diversification." Financial Analysts Journal, January-February 1994, pp. 3-7.
Leibowitz, Martin L. and Terence C. Langetieg. "Shortfall Risk and the Asset Allocation Decision: A Simulation Analysis of Stock and Bond Risk Profiles." Journal of Portfolio Management, Fall 1989, pp. 61-68.

Merton, Robert C. "Lifetime Portfolio Selection by Dynamic Stochastic Programming: The Continuous Time Case." Review of Economics and Statistics, August 1969, pp. 247-257.

Poterba, James and Lawrence Summers. "Mean Reversion in Stock Returns: Evidence and Implications." Journal of Financial Economics, 22,1988 , pp. 27-59.

Reichenstein, William and Dovalee Dorsett. "Time Diversification Revisited." Research Foundation of the Institute of Chartered Financial Analysts, 1995.

Samuelson, Paul A. "Lifetime Portfolio Selection by Dynamic Stochastic Programming." Review of Economics and Statistics, August 1969, pp. 239-246.

Samuelson, Paul A. "Longrun Risk Tolerance When Equity Returns are Mean Regressing: Pseudoparadoxes and Vindication of 'Businessman's Risk" in Brainard, W., Nordhaus, W., and Watts, H. (Editors). Macroeconomics, Finance and Economic Policy: Essays in Honor of James Tobin, MIT Press, 1991.

Siegel, Jeremy J. "Stocks for the Long Run." $2^{\text {nd }}$ edition, McGraw-Hill, 1998.

Thorley, Steven R. "The Time-Diversification Controversy." Financial Analysts Journal, May-June 1995, pp. 68-76.

Vroom, Victor and Bernd Pahl. "Relationship between Age and Risk Taking among Managers." Journal of Applied Psychology, Vol. 55, October 1971, pp. 399-405. 